\title{
Uyumlu Tasarıma Geçişte Kitle İletişim Araçlarının Gelişimi
}

\author{
SELÇUK ILETIŞIM \\ DERGISI 2021; \\ 14(2): 982-1004 \\ doi: 10.18094/ JOSC.869908
}

$[\$$

SELLFIK

ILETISTM

\section{Ali Efe İralı}

ÖZ

Sayısal ortamın fiziksel ve sanal ürünlerindeki geliştirme süreçleri kitle iletişim araçları üzerinde önemli bir etkiye sahiptir. Kitle iletişim araçları üzerinde görülen bu etkiler, uyumlu tasarım yoluyla internet yayıncılığında farklı anlamlar oluşturmuştur. Diğer taraftan, uyumlu tasarım, cihaz, işletim sistemi ve çözünürlük gibi özelliklerden bağımsız olarak özgürce çalışabilen çeşitli ortamlara çok sayıda fırsat sağlamıştır. Bu çalışma, ilgili tasarım sistemini kitle iletişim araçlarının tarihsel arka planı üzerinden incelemeyi amaçlamıştır. Bu nedenle, çalışmada, uyumlu tasarımın ilgili araçlarının kapsamını ve tarihsel gelişimini incelemeyi hedefleyen geniş kapsamlı bir alanyazın taraması gerçekleştirilmiştir. Çalışmanın birinci bölümünde, tarihsel arka planları üzerinden kitle iletişim araçlarının adaptasyon ve çevrimiçi ortam süreçlerinin derlenmesine odaklanılmıştır. Çalışmanın ikinci bölümünde, kitle iletişim araçları ile olan bağlantılarını ve çevrimiçi olanaklarını anlamak için uyumlu tasarım kavramı incelenmiştir. Üçüncü bölümdeyse, günümüz kitle iletişim araçları tasarım sistemleri, güncel uyumlu tasarım yöntemlerini örneklendirebilmek adına kullanılmıştır. İnceleme sonuçları, yeni medya teknolojilerini aktif olarak kullanan kurum ve kuruluşların, farklı alanlarda bir sonraki yeni nesil yayıncılık yöntemlerini de tanımladığını göstermektedir.

Anahtar Sözcükler: Uyumlu Tasarım, Kitle Illetişim Araçları, Web 2.0, Tasarım Dili, Yeni Illetişim Teknolojileri

\author{
ALI EFE IRALI \\ Dr. Bağımsız Araştırmac \\ aliefeirali@yahoo.com \\ ORCID ID: 0000-0001-5332-1367
}

SELÇUK ILETIŞIM DERGISI 2021; 14(2): 982-1004

doi: 10.18094/ JOSC.869908

Geliş Tarihi: 28.01.2021 Kabul Tarihi: 29.03.2021 Yayın Tarihi: 25.04.2021 


\title{
Development of Mass Media in Transition to Responsive Design
}

\section{Ali Efe İralı}

\begin{abstract}
Development processes in physical and virtual products of digital environment have significant effects on mass media. These effects created different meanings on online publishing through responsive design mechanisms. On the other hand, responsive design provided many opportunities to various environments that can operate freely regardless of device, operation system or resolution features. The study was aimed to explore this design system through historical background of mass media. Therefore, a broad range of literature was reviewed to examine the coverage and historical development of mass media together with the responsive design. In the first part of the study, main adaptation to online environment processes of mass media considered to review through its historical development. In the second part, responsive design term examined to understand connections with mass media and its online possibilities. Then in the third part, latest mass media design systems are used to exemplify recent responsive design methodology. The review results showed that institutions and organizations that actively use new media technologies are also defines next generation publishing methods on different areas.
\end{abstract}

Keywords: Responsive Design, Internet Publishing, Web 2.0, Design Language, New Communication Technologies

\author{
ALI EFE IRALI \\ Ph.D. Independent Researcher \\ aliefeirali@yahoo.com \\ ORCID ID: 0000-0001-5332-1367
}

JOURNAL OF SELÇUK COMMUNICATION 2021; 14(2): 982-1004

doi: 10.18094/ JOSC.869908 


\section{Gíriş}

Yeni medya teknolojilerinin gelişim süreci, her araç için biçimde yaşansa da, bugün için ortak bir paydadan söz edilebilmektedir. 0 ortak payda, tasarımsal sürecin oluşturduğu, ekrana ve kullanıma bağı uyumlu tasarım yapılarından meydana gelmektedir. Televizyon, radyo veya basılı tüm araçların, internet teknolojileri kapsamında kendilerine yer bulduğu bu uyumluluk hali için çok farklı teknik dönemlerden geçilmiştir. En nihayetinde, uyumlu tasarım süreçlerine adapte olarak taşınabilir ve masaüstü cihazlar arasındaki engellerin ortadan kalkmaya başladığı bir döneme girilmiştir. Uyumlu tasarımın en önemli unsurlarından olan içerik Yönetim Sistemi (CMS - Content Management System) gibi kullanıcıları programlama yükünden kurtaran ve temel kullanımı yaygınlaştıran özellikler, her geçen gün internet sitelerinin uyumlu tasarıma geçişini hızlandırmaktadır. En çok ziyaret alan ilk bir milyon internet sitesinin \%33'ünün ve tüm internet sitelerinin \%40'ının uyumlu tasarım prosedürlerini içinde barındıran Wordpress isimli içerik sistemini kullanması bunun önemli göstergelerinden biri olmaktadır (W3Techs, 2021; Built With, 2021). Uyumlu tasarım süreci, internet sitelerinin ortak bir dil konuşmasını ve küresel anlamdaki yayıncılık faaliyetlerinin, cihazlar dolayısıyla yaşadığı sorunları ortadan kaldırmayı sağlamaktadır. Bugün taşınabilir cihazlar için üretilen uygulamalar aslında yayınclık faaliyetlerini neredeyse tüm kitle iletişim araçları için çözüyor gibi görünse de, henüz kapsayııılık bakımından net bir cevap sunamamaktadırlar. Glassman ve Shen (2014, s. 79), uygulamaların güncellenebilirlik ve cihaz sürümüne uyumluluk problemleri yaşamalarından dolayı, internet sitelerinin daha önde bir tercih olduğunu açıklamaktadırlar. Benzer biçimde, Almeida ve Monteiro $(2017$, s. 50) da, her cihaz için farklı uygulama ya da site tasarımı yapmanın da maliyet ve teknik açıdan zorlayıcı olması dolasıyıla, uyumlu tasarımın önemli bir cevap olduğunu belirtmektedirler. Bu bilgiler ışığında, kitle iletişim araçlarının uyumlu tasarımı kullanan internet sitesi çalışmalarına kendilerini adapte etme çabalarının, bir sonraki yenilik sürecinin gelişimi hakkında da bilgiler verebileceği düşünülmektedir. Bunu daha iyi anlayabilmek adına uyumlu tasarıma giden yolda, geleneksel yayıncılı̆̆a bağı kullanılan teknolojinin zayıflamasına ya da tip değiştirmesine neden olan gelişmeler alanyazın taraması ile ele alınmıştır. Uyumlu tasarım sürecinin, kitle iletişim araçları açısından bir köprü vazifesi görüp görmediği, tasarım süreçlerinin gelişimi noktasında alınan mesafe ile açıklanmaya çalışılmıştır. Illk örneklerden yola çıkarak, bugüne doğru gelinen yapının incelemesi sağlanmaktadır. Alanyazın taramasından elde edilen bilgiler, neden-sonuç bağlamında derlenmiştir. Çalışmada cevabı aranan ana problem, uyumlu tasarım sürecinin kapsayıcııı̆ının kitle iletişim araçları 
bakımından ne ölçüde gelişim gösterdiğidir. Alanyazın taraması, kitle iletişim araçlarının temel anlamda uyumlu tasarıma doğru giden gelişimlerinin incelenmesi ve internet altyapılarına adaptasyon süreçleri ile sınırlandırılmıştır.

Çalışmanın ilk bölümünde, kitle iletişim araçlarının internet yayıncılığına geçiş süreçleri ve bu süreçte yaşadıkları benzer noktalara yer verilmektedir. İkinci bölümde, 2010 sonrasındaki dönemle birlikte kitle iletişim araçlarını karşılamış olan yeni kullanım ve tasarım süreci olan uyumlu tasarımın açıklaması yapılmaktadır. Uyumlu tasarım süreci ile birlikte internet yayıncılığı çevresinde gerçekleşen temel gelişim süreçleri aktarılmaktadır. Üçüncü bölümde, internet üzerindeki tasarımsal varlığın kullanııılar nezdinde kabul görebilmesi adına yayıncılar tarafından oluşturulan temel tasarım süreçleri açıklanmaktadır. Sonuç ve Öneriler bölümündeyse, mevcut sektörel ilerlemenin nihai değerlendirmesi ile birlikte, gelecek çalışmalara dair öneriler aktarılmaktadır.

\section{KITLE ILETiŞiM ARAÇLARININ INTERNET YAYINCILIĞINA UYUM SÜREÇLERi}

Sanal ortam faaliyetlerinin yayıncılık açısından internet üzerinde başlamasına dair iki yayın kurumuna ait bilgiler bulunmaktadır. Ancak internetin yaygınlığının ve dönem şartları altında kontrol edilebilirliğinin sorgulanabileceği sebebiyle, farklı disiplinlerde yayıncılık gerçekleştirmiş küçük segmentteki kurumların da varlığı unutulmamalıdır. Bu anlamda bilinen ilk gazete odaklı sanal ortam yayıncılık faaliyetini, Laakaniemi'nin (1981) çalışmalarında belirtmiş olduğu üzere, ABD'deki CompuServe isimli bilgisayar firması ve The Columbus Dispatch isimli yayın kuruluşu teşkil etmektedir. Ancak belirli bir internet ortamından farklı olarak; yazılımsal bir tabana dayanan bu çalışmalar, Laakaniemi'nin de çalışmalarında söylediği üzere 1980 yılında başlamış ve uzun bir süre daha, çok sayıda gazete kuruluşunun katılımı ile birlikte devam etmiş̧ir (1981, s. 61-62). Tamamen çevrimiçi teknoloji ile donatılmış ilk örnek ise, Cassidy'nin (2005) çalışmalarında aktardığı üzere, Chicago Tribune isimli gazete ve dönemin en büyük sayısal ortam şirketlerinden biri olan America Online (AOL) tarafından yapılan ortak girişim Chicago Online isimli elektronik gazetedir. Illgili çalışmada Mayıs 1992'de yayın hayatına başladığı belirtilen yayın, sanal ortam gazeteciliğine/yayıncılığına dair de temel başlangıç noktasını teşkil etmiş̧tir (2005, s. 264). Carlson'ın (2003, s. 49-50) belirttiğine göre bugünkü internet teknolojilerine adapte olan ilk sistem ise, 19 Ocak 1994 ylında Amerika Birleşik Devletleri'nin Kaliforniya eyaletinde internet üzerinde ücretsiz yayına başlamış olan Palo Alto Weekly'dir. Türkiye'de gazetenin tamamını çevrimiçi 
olarak veren ilk gazeteyse, Milliyet Gazetesi olmuştur (Gönenç, 2003, s. 96). Internet arşivleri incelendiğinde (Milliyet Gazetesi, 1996), gazetenin 25 Kasım 1996 tarihinden itibaren sanal ortamda günlük tekil güncelleme ve sayı usulüyle uygulama yaptığı anlaşılmaktadır. 2000 yılı sonlarına kadar (Ekim ve Kasım ayları) basılı gazete ile ortak olarak internet üzerinde yayının sürdüğü; daha sonra basılı ortamdan ayrılan haberlere ve yazılara da yer vermeye başladığı görülmüştür.

Veri paylaşımını daha da genele yayma çabaları sadece yazılı basında değil, televizyon sektöründe de yer bulmuştur. Televizyon yayıncılığındaki ilk yazılı veri transferi örneklerinden birini teleteks (teletext) oluşturmaktadır. Teleteks sistemi ilk olarak Teledata, daha sonra ilk resmi uygulama ismi olan Ceefax ismiyle pazarda yerini almıştır (Carlson, 2003, s. 33; BBC, t.y.-a), 1971 ylında BBC tarafından patenti alınmış olup; İnternet üzerinden gerçekleştirilen yazılı materyallerin idealine giden yolda önemli bir rol üstlenmiştir. 1979 yılında BBC televizyonu üzerinden gerçekleştirilen altyazı mekaniğiyle de kendisini gösteren sistem, hali hazırda devam etse de ekrandaki çözünürlük ve yazı tipi kısıtları dolayısıyla büyük sorunlara sahiptir (Hughes, Armstrong, Jones, \& Crabb, 2015, s. 1). Teleteks sisteminin gelişmiş bir sürümü olan videoteks teknolojisi de yine televizyon üzerinden yayın yapan çevrimiçi sistemlerden olmuştur. Genel anlamda 1986 yılına kadar devam ettirilmiş sistemin örnekleri, Carlson $(2003$, s. 34,39,41)'a göre yüksek maliyetler ve evlerde o zaman için genel olarak bulunan az sayıdaki ya da tek televizyonu doğrudan işgal etme gibi özellikleri dolayısıyla pazarda tutunamamıştır. Zamanla 1990'lı yıllarda televizyon açısından ev kullanıcıları için farklı bir dönem açılmıştır. İnternetin yavaş yavaş perakendeye yayılmasının da etkisiyle, televizyon için yeni bir fırsat sahası ortaya çıkmıştır. Televizyonların izleyiciler ile karşııklı etkileşim oluşturmasını sağlayan stratejiler üretilmiştir. Bunlardan önemli olarak nitelenebilecekler, Amerika Birleşik Devletleri televizyonlarında ekrana gelmiş olan Wheel of Fortune ve Jeopardy televizyon programlarıdır (Gibbs, Hoch, Le Van Gong, Rafey, \& Wang, 2001; van Vliet, 2002). Van Vliet (2002)'e göre, ilgili programların internet üzerinde HTML ve Javascript programlama altyapılarını kullanmak suretiyle eşdeğer karşılıkları oluşturulmuştur. Bu süreçten sonra internet, 2000 'lerin ortalarından itibaren daha geniş kitlelerin evine girmeye ve televizyon teknolojisi ile daha yakın bir etkileşime girmeye başlamıştır. Bu dönemlerde IPTV (Internet Protokolü Televizyonu), IDTV (Interaktif Sayısal Televizyonculuk) veya ITV (Interaktif Televizyon) gibi isimlerle, internetin televizyon ile buluşmasını sağlayan çok sayıda çalışmanın başlangıı yapılmıştır (Ma, Wilkes-Gibbs, \& Kaplan, 2004; van Dijk \& Vos, 2001). Ilgili uygulamalara dair ilk büyük örneklerinden biri olarak Yahoo! 
tarafından 2003 yılında Japonya'da Broadband TV (BBTV) ismiyle başlatılan yayıncılık faaliyeti gösterilebilir. Bu faaliyet, Japonya'daki televizyon kanallarının çevrimiçi ortamda kullanııılara ulaştırılmasını sağlamıştır (Kinugasa, Motohashi, Yeong-Wha, \& Terada, 2010). Türkiye'de ise kablo yayın altyapısı gereğince IPTV konusunda Türk Telekom ve Superonline görevlendirilmiştir. Türkiye'deki IPTV kullanımı 2018'in ikinci yarısından itibaren Kablo TV yayınlarını geçmiş; 2020 ilk çeyrek itibarıyla toplam 1.550.366 aboneye ulaşmıştır (Bilgi Teknolojileri ve Iletişim Kurumu, 2020). Sistemin yaygınlaşarak yüksek çözünürlük seviyelerine erişmesi (720p ile 1080p arası yayın transferleri için), DSL (Digital Subscriber Line - Sayısal Abone Hattı), ADSL2 (Asimetrik Sayısal Abone Hattı) ve VDSL (Çok Yüksek Oranlı Sayısal Abone Hattı) gibi standart hızdan çok daha yüksek hızlardaki (16-64 MB/s) altyapıların gelişmesini beklemiş̧ir. Aynı süreç içinde ilgili sistemlere alternatif olarak taşınabilir cihazlardaki televizyon uygulamaları üzerinden, indirilebilir içerik olarak sunulan yayıncılık türleri de oluşmaya başlamıştır. Devamında da P2P (peer to peer - eş kullanıcılar arası) ismi verilen ve yayına bağlanan her bir kullanıcının sunucu vazifesi görmek suretiyle, farklı kullanıcılara veri gönderip onlardan veri alabildiği internet yayıncılığında artışlar olmuştur (Xiao, Du, Zhang, Hu, \& Guizani, 2007, s. 127-130). Zamanla televizyon üzerinden doğrudan internete erişim perakende pazarında yerleşmiş olsa da, gerek kontrollerin zorluğu gerekse de, erişim için kullanılan menülerdeki optimizasyon eksikliği dolayısıyla, kullanııların televizyon üzerinden internete ve internet yayınlarına ulaşmak istememeleri, çeşitli çalışmalarda dile getirilmiştir. Buna çözüm olarak, uyumlu tasarımın temel prensipleri kullanıldığında, başarııı bir televizyon kullanıcısı deneyimi oluşturulacağına yönelik çalışmalar yapılmıştır (Perakakis \& Ghinea, 2015, s. 38-40).

Gazete ve televizyon kuruluşlarının ardından, radyo da yine 1990'ların ortalarında kendisine internet ortamında yer bulmaya başlamıştır. 1993 yılında Amerika Birleşik Devletleri'nde "Internet Talk Radio" (İnternet Sohbetleri Radyosu) isimli çalışma, alanındaki ilk çevrimiçi radyo istasyonu olarak gösterilmektedir. Haftalık 30'ar dakikadan oluşan program süresince güncel teknolojik bilgiler ve internet temalı konuşmalar gerçekleştirildiği, program kaydının da daha sonra dinlenebilir halde depolandığı bilinmektedir (Sawhney \& Lee, 2005, s. 400; McKinney, Barnas, \& Golub, 1994, s. 634; Ginsburg, 1997). Türkiye'de internet gazetelerinin ardından radyo bakımından da 1990'ların ortalarında girişimler başlatılmıştır. Bu anlamda internet üzerinden yayın yapan ilk yerli radyo, 1996 yılında Radyo ODTÜ olmuştur (Hatipoğlu, 2009). 1998 yılındaysa, diğer bir uygulama iтü Radyosu tarafından 
gerçekleştirilmiştir (iтü Kio, 2020). En nihayetinde gazete, televizyon ve radyonun ardından, doğrudan internet üzerinde oluşan sosyal paylaşım platformlarının da 1990'ların ortalarında çıktığı görülmektedir.

İnternet üzerindeki ilk büyük sosyal paylaşım merkezlerinden biri olan Geocities, sosyal paylaşım tecrübesine dair temel noktaları oluşturmuştur. Milligan'ın (2017) aktardığına göre Geocities ilk olarak 1994 yllında ABD'nin Kaliforniya eyaletinde David Bohnett'in girişimiyle "Beverly Hills Internet" isminde hayata geçmiştir. İsmini 1995'te değiştirmesinin ardından, 1997 yılına kadar geçen sürede 100 kat büyüme oranıyla tam 1 milyon kullanıcı sayısına ulaşmıştır. 1998 yılının Ağustos ayında halka açılan şirket 1999 yılının Ocak ayında Yahoo! tarafından 4.6 milyar dolara satın alınmıştır (2017, s. 139-140). Rakiplerin ve daha önce mevcut sistemi deneyenlerin olmasına rağmen, dünya çapında böylesine büyük bir satın alma operasyonuna sayısal ortamda sıklıkla rastlanılmamıştır. Güçlü bir sermaye desteğiyle oluşturulan reklamlar sayesinde kısa sürede oldukça büyümüş, tüm dünyadan kullanıcıların ilkuğradıkları adreslerden biri olma özelliğini elde etmiştir. Temel anlamda kullanıcılara kendi internet sitelerini kurmaları ve birbirleri ile topluluk oluşturmaları üzerine bir felsefenin de temellerini atmıştır. Site tabiri, kullanııların konakladıkları sokaklara, caddelere benzetilmiştir. Bu toplulukların liderleri ile birlikte bir iletişim devamlılığı sağlanması planlanmış, bu özelliği ile bütün piyasa rekabetini kırmayı başarabilmiştir. Milligan, GeoCities'in içinde bulunduğu durumu, oluşturulan her topluluğun homojen bir yapıda tutulması ile açıklamaktadır. Bunun için de topluluk liderleri (admin ve benzeri yöneticiler), ziyaretçi defteri (mesaj paylaşımı sağlanan küçük not alanları) ve topluluk ödülleri (en çok paylaşım yapan veya belirli bir konuda bir faaliyet gerçekleştiren gibi) şeklindeki üç kriterin önemli rol üstlendiğini söylemektedir (2017, s. 151). Schneider ve Bruton (2006), aynı yıllarda GeoCities'in çalışma prensibine benzer bir başka platformun da Cornell Üniversitesi öğrencileri tarafından şekillendirildiğini aktarmışlardır. Haber bültenleri, sohbet odaları ve sanal sanat galerileri gibi özellikleri barındırmış olan theglobe.com adresinin 2001 yılında ekonomik alandaki durgunluk ve reklam veren sayısındaki azalma nedeniyle kapandığı belirtilmektedir (2006, s. 1). Tabii ki ekonomik anlamda günceli yakalayabilmek, başarının tek anahtarı olmamaktadır. Mevcut teknik altyapının da sistemi ileriye taşıyabilecek ek desteklere intiyacı olduğu açıtır. Bu açıdan bakıldığında GeoCities'in sahibi Yahoo! ile Google arasında yaşananlar da, başarılı bir gelir noktasına ulaşabilmenin temel unsurları konusunda fikir vermektedir. 1998'de elinde GeoCities'i bulunduran Yahoo!, Google'ı 1 milyon dolara satın alma teklifini geri çevirmiş (Derrick, 2016); buna karşın Google ise 2003 yılında Pyra Labs tarafından 2001 yılında kurulan Blogger'ı satın alarak büyümesine devam etmiş̧ir 
(McIntosh, 2003). Çok kısa süre içerisinde Yahoo! ve Google özellikle Web 2.0 teknolojilerinin ortaya çıkmasıyla birlikte rolleri değişmişlerdir. Yahoo!'nun bir diğer geri çevirdiği teklif ise 2008 yılında Microsoft tarafından önerilen 46 milyar dolara satın alınmasıdır ki (Foley, 2011); şirket bu teklifin üzerinden on yıl geçmeden, 2017 yılında Verizon isimli teknoloji ve iletişim şirketi tarafından 4.48 milyar dolara satın alınmıştır (Kharpal, 2017). Tabii GeoCities bu yılları göremeden çok daha önce yayın hayatına son vermiştir.

GeoCities'in büyümesindeki önemli bir özelliği olan, 1998 ylında hizmete giren ve WYSIWYG altyapısı bulunan GeoBuilder isimli "kendi siteni kendin hazırla" modülü pek çok kullanıcının hayatında yer edinmiştir. Ancak 1999'daki satın alma işleminin ardından Yahoo!'nun yaptığı değişiklikler ve çağın getirdiği yeniliklerin ardında GeoCities istenen performansı bir türlü eskisi gibi yakalayamamıştır. Topluluklar arasındaki bağlantılar sekteye uğramış, öte taraftan yeni çıkan internet sitesi sağlayıııları, GeoCities'in etkinliğini kırmaya başlamıştır. Ücretsiz iletişim ağı olma cazibesini kaybeden GeoCities de 2009 yııında kapatılmış, bütün verileri herhangi bir yedekleme mekanizması kurulmaksızın silinmiştir (Milligan, 2017, s. 140-142,151). Google'ın Blogger'ı başta olmak üzere, daha birçok Web 2.0 ortamının, GeoCities'in pazardan çekilmesine etki ettiği söylenebilir. GeoCities'in Türkiye'deki bir benzeri olan sitemynet.com da aynı kaderi paylaşmıştır. Türkiye'nin önemli teknoloji ve haber portallarından olan Mynet'in 2001 yılında pazara sunduğu MySite ya da diğer ismiyle SiteMynet, 2011 yılında kapanmıştır. Yükselişi de tıpkı GeoCities'e benzemesi yönüyle önemli olan MySite'nin, topluluk idaresi açısından da benzer bir yol izlediği gözlemlenmiştir. Ziyaretçi defterleri, sohbet odaları ve daha birçok eklentiyi bünyesinde barındırmıştır.

Peki, GeoCities ve benzerlerinin yayıncılık faaliyetleri açısından önemi nedir? Bu sorunun üç cevabı olduğu söylenebilir. Birincisi, bireylere kendi imkânları dâhilinde diledikleri gibi fikirlerini aktarabilecekleri ve dünyanın farklı köşelerindeki kişilere istedikleri konularda görüşlerini beyan edebilecekleri bir oluşumun, kişisel blogların farkındalığının önünü açmış olmalarıdır. İkincisi, yayıncılık adına internet üzerinden belirli tipte konuların güncel olarak paylaşılabilmesi ve bunların kitlelerce takip edilebilir olması kavranmaya başlamıştır. Üçüncüsü ve en önemlisi ise, günümüzdeki en temel problemlerden biri olan teknoloji ile omuz hizasında hareket etmemenin ve kullanıcıların ihtiyaçlarını göz önünde bulundurmamanın ne gibi sorunlar doğurabileceğinin kanıtını sunmuş olmalarıdır. Bu üç noktaya odaklanılması, günümüzdeki perakende zincirlerinde satılan donanımlar ile sanal ortamda 
konuşlandırılmış yazılımlar arasındaki doğrusal başarı bağlantısı hakkında öngörüler elde etmemiz için deliller sunabileceği düşünülmektedir.

Teknolojinin takibi ve gerekliliklerine adaptasyon, pazardaki payın muhafazası ve kullanıcıların bilgiye erişimindeki engellerin ortadan kalkması için en gerekli eylemleri kapsayan bir dizi önlem paketinden oluşmaktadır. Yeni medyanın parçalarının siteler içerisine entegrasyonu, arama motorlarına yapılacak reklam yatıımları, kullanıcılar ile yakın iletişim kurma gibi yaygın ve görünen önlemlerin arkasında, tasarımsal süreçleri de içermektedir. Temel tasarım süreçleri bu yönüyle ikiye ayrılıyor da diyebiliriz. Birincisi tüm planlamanın ve nihai kullanıma açılacak sistemin programlandığı gerideki kısım ve nihai kullanıııarın muhatap olacakları ön tasarımsal kısım. Bu iki bölüm de ortak bir paydaşa kullanıcı açısından sahip olsa da, farklı ortamlar üzerindeki bağlantının sağlıkı kurulabilmesi için iyi bir planlama ile şekillendirilmiş olması gerekmektedir. Diğer taraftan, renk, metin ve görsellerin seçilmesi, iyi görüntü sergilenmesi gibi eylemler, bu planlamanın en son aşamalarını simgelemektedir. Mevcut elektronik belgeler üzerine yapılan veri transferlerinde, en önemli husus, hazırlanacak içeriklerin yerleştirilecekleri alanların tasarımı ve platformlar arasında sıkıntı yaratmayacak sonuçlar ortaya çıkarmasıdır. Uyum, tıpkı PDF (portable document format - taşınabilir belge formatı) formatında olduğu gibi çapraz işletim sistemlerinde çalışabilirliktir. Sorun yaşatan unsurlar ise Flash formatında karşılaşılan güvenlik sorunları ile çapraz platform desteğinin olmaması şeklinde örneklendirilebilir.

\section{UYUMLU TASARIM}

Geleneksel yayıncılık faaliyetlerinde, masaüstü yayıncılık yazılımları ile düzenlenen ürünlerin baskı aşamasında tek bir çıktı için hazırlandığı varsayılabilir. Örneğin kitap bir kerelik basım işlemine girmektedir. Ancak elektronik ortam her geçen gün kendini mevcut pazardaki eğilime göre değiştirmektedir. Böylece farklı tipte cihaz yapıları ile farklı alanlarda tekrar tekrar üretim devam ettirilebilmektedir. Bu sadece yazılı araçlar için değil, radyo ve televizyon gibi ses ve görsel ağırlıklı araçlar için de geçerlidir. Ancak teknik ilerleme sebebiyle, tüm bu çalışmaların özellikle internet sistemlerini kullanarak devamlılıklarını sürdürebilmeleri, çeşitli yazılımsal mekanizmalara bağlıdır. Dolayısıyla, platformlar arasında bir yeni form üretimi ihtiyacı mevcuttur. Standalone (işletim sistemlerinde, eklentilerden bağımsız tek başına aktif edilebilen, özerk yapıı (Türkiye Bilimler Akademisi, t.y.-a) şeklinde de alanyazında yer alan yazılımsal uygulamalar, bu anlamda önemli bir kolaylığa sahiptir. Çünkü, Apple 
Store ve Google Play gibi ortamlardan indirilen uygulamalar, program yapıları gereği, yüklendikleri cihazların ekran görüntülerine ve işlem yapılarına göre kendilerini adapte edebilen türlerde çalışmaktadırlar. İnternet siteleri ve siteler üzerinden yayın yapan basın yayın kuruluşları için ise süreç farklı biçimde ilerlemektedir. İnternet siteleri bir yazılım olarak değerlendirilseler dahi, yapıları gereği dinamik olup; eklenti adı verilen yan uygulamalar ile birlikte çalışmaktadırlar. Yan uygulamalar, kod yapılarını etkilediğinden dolayı, gerek güvenlik gerekse de daha güncel olma çabası açısından sürekli biçimde yenilenmektedirler. Uyumlu tasarım süreci de bu yenilenme çalışmalarının bir sonucudur denilebilir. Dolayısıyla da, internetin dinamik yapısı, geleneksel anlamdaki indirilen uygulamaların süreçleri ile bir tutulmamalıdır. Bu yüzden internete dair tasarımsal süreçleri incelemek, mevcut teknolojiler arasındaki endüstriyel bağlantının sağlıklı biçimde anlaşılabilmesi adına da büyük önem arz etmektedir.

İnternet sitelerinin tasarımlarına dair oldukça geniş tanımlamalar mevcuttur. Süreçlerin isimleri ve tanımları, uygulama tipleri oldukça fazla sayıda çeşitlilik göstermektedir. Ancak temel tasarım stratejileri açısından bilinen ayrımlardan ilki "kademeli geliştirme" (progressive enhancement) ve "hafifçe/zarar vermeden indirgeme" (graceful degradation) olarak adlandırılmaktadır (Nebeling \& Norrie, 2013, s. 511). Kademeli geliştirme, tasarımın aşağıdan yukarıya doğru bir süreç almasını ifade etmektedir. Diğer bir deyişle, en küçük akıllı cihazların üzerindeki testlerden yola çıkılarak bütün mevcut tarayııılarda çalışması istenen bir sistem yaratılması esasına dayanmaktadır (Heilmann, 2009). Hafifçe indirgeme ise, tasarımın, yukarıdan aşağıya yapılan testler sonucu, en güncel tarayıcıdan başlayarak diğer tarayııılar üzerinde çalışır hale getirilmesi prensibine dayanmaktadır. Masaüstünden başlayıp; taşınabilir cihazlara indirgenen sistemler şeklinde de düşünülebilir. Hafifçe indirgeme sürecinde, çıkacak aksaklıklara karşın alınabilecek ek tedbirler ile bir yol haritası çizilmesi beklenirken; kademeli geliştirme fikri, tüm cihazlar için tek bir kod yapısı ve mekanizma ile tasarlanmış internet siteleri oluşturulması üzerine şekillenmiş̧ir. Steven Champeon ve Nick Finck tarafından, 2003 yılında gündeme getirilmiş olan kademeli geliştirme prensibi, yıllar sonra, günümüz internet sitelerini kontrolü altına alan tasarımsal sürecin başlangıç stratejisini oluşturduğu bilinmektedir (Parker, Toland, Jehl, \& Costello Wachs, 2010, s. 26-27).

Kademeli gelişim ve indirgeme süreçlerini takiben gelen stratejiler ise "mobile first" "taşınabilir öncelikli" (mobile first), "yoğunlaştırılmış / sıkılaştııılmış tasarım" (hardboiled design) ve de "uyumlu 
tasarım" (responsive design)'dır (Alston, 2012, s. 240). Taşınabilir öncelikli, isminden de anlaşılabileceği gibi, taşınabilir cihazlara adapte edilmesi gereken sistem, strateji olarak taşınabilir cihazların hedef alınması gerektiğini vurgulayan planlamaları simgelemektedir (Graham Longo, 2012). Yoğunlaştııımış tasarım ise, Clarke'ın $(2010$, s. 5) çalışmasında yaptığı tanımıyla, en iyi olarak çalışması gereken sistem ideali yerine, sistemin sınırlarının zorlandığı ve hataların bulunarak yeni kurallarla geliştirilen çok daha teknik planlamaları ifade etmektedir. En nihayetinde tüm bu planlama süreçleri, sosyal medya adıyla 2006'dan sonra genişleme imkânı bulan internet teknolojilerinin aynı düzleminde yenilenerek değişim göstermiştir. Özellikle kod yapılarında görülen yenilikler ve birbiriyle uyumlu çalışacak şekilde tasarlanan sistemler, tüm geçmiş planlama stratejilerini aynı potada eritecek bir fikrin doğmasına sebebiyet vermiştir. Tanımı ve yakınlığı bakımından, en çok kademeli gelişim fikrine benzeyen akımın ismi "responsive design", alanyazındaki karşıllı̆ıyla (Türkiye Bilimler Akademisi, t.y.-b) "uyumlu tasarım" olmuştur.

2000'lerin başından itibaren, yeni medya kavramının yaygınlaşmasına kadar geçen süreç içerisinde, cihazların birbiriyle kurdukları iletişimde kullanıcıların sağlıklı veri alışveriş̧i gerçekleştirmesi adına çok sayıda çalışma yapılmış; öneriler getirilmiştir. Tasarımın yazılım mimarisindeki teknolojik değişim sebebiyle bu planlar ve öneriler sürekli biçimde değişiklik göstermişlerdir. Ancak 25 Mayıs 2010 tarihinde, Ethan Marcotte'nin uyumlu internet sitesi tasarımlarına dair hazırladığı yazısında (Marcotte, 2010; Bryant \& Jones, 2012, s. 37) dile getirilen uyumlu tasarım süreci, temel anlamda bir birlikteliğin, yekpare hareket etmenin başlangıcı olmuştur. Uyumlu tasarım süreçlerinde, telefondan bilgisayara, tüm farklı cihazlarda, görüntünün mümkün olabildikçe optimize edilerek kullanılmasının sağlanmasına yönelik yöntemler anlatılmıştır (Voutilainen, Salonen, \& Mikkonen, 2015, s. 60).

Uyumlu tasarım süreçlerinden önce, mobil cihazlara dair sunulan çözüm önerilerinden biri "pixelperfect" şeklinde tabir edilen, net çözünürlük değerleri taşıyan tasarım planları olmuştur. Buradaki netlik kavramı, görüntüye yakınlaşıldığında ya da ekran çözünürlüğüne göre uzaklaşıldığında, bir flulaşma ya da kırılma yaşanmamasıdır. Grafiksel anlamda en küçük görüntü / kare birimi olan piksellerin birleşmesi ve ekrana yayılması ile elde edilen görüntü alanını ifade eden çözünürlük için belli başlı çalışmalar yapılmasını ifade etmektedir. İleri seviye kodlama yapılarından ziyade, mobil tasarımlara uygun olarak nitelenen ekran çözünürlüğü değerlerinde yapılan tasarımların, kullanııların giriş yaptıkları cihazlarca otomatik olarak algılanıp; yönlendirilmesi esasına dayanmaktadır. Sitenin birebir benzerini yapma 
esasına dayanan bu sistemlerde, tasarlanan ölçülerin dışında çözünürlük değerlerine sahip ekranlarda, çalışmaların görüntülerinde bozulmalar oluşmaktadır (Kim, 2013, s. 29-30). Uyumlu tasarım süreçlerinde ise, tek bir sayfada yekpare kod dizilimi ile, bütün cihazlara uyum gösterme hedefi mevcuttur. Kod ile karşılaşan cihazlarda, çözünürlük, kullanııının ekranının çözünürlüğüne tepki verir. Daha sonra, sayfanın sistemi, verilerin yerlerini değiştirme ve kimini göstererek, kimini gizleme yoluna gider. Diğer bir ifade ile kendini, kullanııların cihazlarına uyumlu hale getirmeye çalışır (Bernstein \& Klemmer, 2014, s. 119). Groth ve Haslwanter (2016) ve Kim (2013), çalışmalarında, Marcotte'nin üç önemli nokta üzerinde durduğunu ifade etmektedirler. Birincisi, geometrik açıdan kare ya da dikdörtgen şekilli, sayfayı belirli kısımlara bölerek; hizalama yapmaya yarayan ve tıpkı geleneksel masaüstü yayıncıllğının dizgi işlemlerinde kullandığı doğru parçalarına benzeyen ızgara şeklindeki noktaların oluşturulmasıdır. Teknik anlamdaki bu ızgara (grid) bölümlerine, ilgili yazıı ve görsel içeriğin yerleştirilmesini takiben; farklı çözünürlüklerde, genişleme veya daralma esnasında tepki gösterebilmesi sağlanmaktadır. İkincisi, durağan olmayan hareketlendirmeye ve esnetilmeye müsait görsellerin kullanılması ve bu görsellerin, kodlama vasıtasıyla büyültülüp küçültülmesine olanak sağlanacak sistemin üretilmesidir. Üçüncüsü ise, kullanılacak araçlara (görsel, yazı veya diğer benzer araçlar) dair tanımlanacak kod dizilimleri oluşturulması ve böylece farklı cihazlarda neyin nasıl görünmesinin gerektiğinin belirlenmesidir (Groth \& Haslwanter, 2016, s. 208-209; Kim, 2013, s. 30-33; Marcotte, 2010).

Uyumlu tasarımın çalışma prensibi, HTML ve CSS kod dilleri ile bütünleşik ve dinamik bir yapı oluşturulmasından geçmektedir. HTML (hypertext markup language), sitenin içeriğini ve temel iskeletini barındırırken; CSS (cascading style sheets) HTML içerisinde yer alan bölümlerin konumlandırmalarını, renklerini, boyutlarını ve reflekslerini/tepkilerini belirleme rolünü üstlenmektedir. HTML içerisinde oluşturulan yayın içeriği, CSS ile birlikte belirli bir düzende ve sınıflandırmada görüntülenebilmektedir. Daha da öteye gidildiğinde, uyumlu tasarım sayesinde ilgili kodlanmış içeriğin yerlerinin tekrardan değiştirilmesi sayesinde uyumlu tasarım elde edilmektedir. Örneğin, 1000 piksel değerine sahip bir ekranda, 200 piksel değerine sahip içerik kutuları oluşturulmasını ve bunların taşınabilir cihazlarda alt alta veya yan yana veyahut slaytlar şeklinde yer alıp almamasını CSS belirlemektedir. Masaüstü ekranlarda ya da, ilgili örneğe istinaden elde edilecek bir 1000 piksellik ekranda, iki içerik kutusu yan yana gösterilecek iken; tablet veya akıllı telefon içerisinde iki kutudan sonra gelen yer değiştirerek bir alta geçmesi sağlanacaktır (Walsh, McMinn, \& Kapfhammer, 2015, s. 709-710). Bu sayede, sitenin içeriğini 
bozmadan bütün bilgiler kullanıcılara ulaştırılmış olacaktır. Özellikle uluslararası alanda büyük gazetelerin internet sitelerinin çalışma prensipleri bu şekilde kurgulanmıştır. Diğer ticari örnekler ise perakende piyasasında hizmet gören işletmeler ile hızı tüketim malları sağlayııılardır. Gelinen noktada, özellikle 2014 sonrasında HTML dilinin 5. sürümünün yaygınlaşmasını takiben, Javascript isimli programlama dilinin, kod yapısı sayesinde HTML5 ve CSS3 dilleri ile uyumunun yükselmesi gerçekleşmiş, Flash pazardan çekilmeye başlamıştır. Böylece, mevcut pazardaki tüm gerçek ve tüzel kişilikler kendilerini bu sürece entegre etmeye başlamışlardır. Flash altyapısını kullanan flip book uygulamaları da HTML5 teknolojisi ile şekillenmeye başlamış, uyumlu tasarıma kendisini adapte etmiştir. Diğer yandan kodlamanın tek bir noktadan yönetilebilmesi ve güncellemenin kolaylaşması, taşınabilir cihaz ve masaüstü için ayrı ayrı siteler kurulmaması, kullanıcılar için daha rahat hareket edebilme olanağı sunması, yakınlaşma ve boyutta farklılıktan doğan görüntü bozulmalarının önüne geçilmesi şeklinde ortaya çıkan faydalarını özetleyebiliriz (Kim, 2013, s. 30-32). Tüm bu süreçleri daha olumlu bir gelecek beklentisi içerisinde karşılamak gerekmektedir. Geçmişten örnek verecek olursak; taşınabilir cihazların süreci bize bu konuda başka bir örnek sağlayacaktır.

Akıllı telefonların ilk piyasa hareketlerinde, internet sitelerine dair doğrudan bağlantı sağlayan ve sanki masaüstü platformlarmış gibi tepki gösteren cihazların, aslında çok fazla yükle karşılaştı̆̆ı bilinmekteydi. Davranışsal açıdan, yazıımların endüstriye adapte olması kısa da olsa belli bir süre almıştır. Bu sebeple, internete bağlanan cihazların sabit eylemlere sabit tepkiler vermesi en sık rastlanan durumdu. Zamanla, çalışmalardaki beklentiler de gösteriyor ki, üreticiler ve yazılımcılar farklı tipteki uygulamalara ve objelere farklı ayarlamalar ile müdahale etmeyi başarabilmişlerdir. Elektronik yayın okuyucu cihazlar ile akıllı telefonların perakendede yükselişe geçtiği 2007-2008 tarihlerindeki araştırmalardaki beklentiler de bize bunları göstermektedir. Cihazlar ve yazılımları, bağlandıkları materyallere, performansı yükseltecek tepkiler göstermeli tezleri savunulmuştur (Somers \& Paul, 2008, s. 795-796). Nitekim uyumlu tasarım ve beraberinde gelen teknik yenilikler sayesinde, hem kullanıcılar hem de üreticiler aynı feraha kavuşmuş oldular.

Dergiler ve kitaplar için büyük bir yayılım ortamı vaadinde bulunan uyumlu tasarıma sahip internet siteleri, arama motoru optimizasyonlarından sonra oldukça önemli hususlardan bir başkasını teşkil etmektedir. Bu önemi ispatlamak üzerine çeşitli çalışmalar yapılmıştır. Daha iyi ve daha rahat biçimde incelenebilir olan bir ortam üzerine çok sayıda bağımsız kişi ve kurum, yazılımsal iyileştirmeler 
gerçekleştirmiştir. Ancak uyumlu tasarım profili dışında kalan her yöntemin, görüntü ve içeriğin hedefine ulaşmasında sıkıntı yarattığı tespit edilmiştir. Bu çalışmalardan, yayıncılığa odaklı önemli örneklerden biri Aalto Üniversitesi'nden Kuhna, Kivelä ve Oittinen (2012, s. 386-387) tarafından 2012 yılında gerçekleştirilen otomasyon testidir. Yapılan çalışmada, mevcut geleneksel internet sitesinin, otomatik olarak belirli yönergelerle oluşturulmuş sürümü ile tamamen uyumlu tasarım şartları altında oluşturulmuş sürümü arasındaki inceleme yer almıştır. Kullanıcı istatistiklerinin paylaşıldığı çalışmanın sonuçları incelendiğinde, kullanım rahatlığı, sadelik, anlaşılabilirlik, şablon kullanım kolaylığı gibi faktörlerle birlikte, uyumlu tasarım prensipleri ile oluşturulmuş çalışmanın daha başarılı olduğu kanaatine varılmıştır. Hali hazırda masaüstü yayıncılığın temel dizgi prensiplerini tamamen içeriğinde barındırması sebebiyle dahi başlı başına bir tercih olarak kullanılması gereken uyumlu tasarımların, 2017 şartları altında, vazgeçilmez bir unsur olduğu anlaşılmaktadır. Günümüzde bu yapıyla çalışmak isteyen kullanıcılara, içeriğinde uyumlu tasarımlarda kullanılabilecek tüm menü, renk ve iletişim mekaniklerini bulunduran çatı/çerçeve ön yüz sistemleri (framework) sunulmuştur. illgili çerçeve sistemlerinde, Javascript kod dili kullanılmak suretiyle, internet sitelerinin temel ihtiyacı olan kod düzenekleri hazır şablonlar halinde sergilenmektedir (Sarkis, Concolato, \& Dufourd, 2017, s. 5). Bu ve benzeri sistemlerin kullanım sıklığının artması ve kullanıcı bazında yaygınlaşması ile yayın araçlarının kendine bir yaratım sahası bulması gün geçtikçe daha da kolay hale gelmeye devam etmektedir.

Çevrimiçi ortamın olanaklarından hem internet sitesinin hem de uygulamalar bazında yararlanmaya devam eden basının, çevre sektörlerle de bağlantı kuran bir yapı sergilemesi, varlıklarını sürdürebilmeleri için gereklidir. Diğer taraftan, reklamın sanal içeriklere entegre edilmesi gibi sıkıntıı süreçlerin artık neredeyse tamamen ortadan kalkması ile birlikte, bu mecralar üzerinden yayın yapan gerçek ve tüzel kimliklerin beklentileri de yükselmeye devam etmektedir. Geriye kalan tek husus, reklamların alınabilmesi için oluşacak görsel planlamanın yanındaki muhtemel dikkat çekici içeriklerin oluşturulmasının sağlanmasıdır. O da, teknolojiye adapte olma süreci içerisinde, diğer alanlardan faydalanma ve mevcut teknolojiler hakkında çıkan çalışmaları takip ile mümkündür. Okuyucunun, yeni teknolojiler ile buluşturulması ve uygulamalar bazında baş aktör konumunda paydaşlık sahibi yapılması, bu süreç içerisinde bir devamlılık sağlayacaktır (Tomas, 2013, s. 309,314). Önemli nokta, endüstrinin kendi zamanını belirlemesi ve mevcut piyasanın tüm tarafları ile bir bütünlük oluşturmasıdır. Taşınabilir cihazların 50 seneyi aşkın gelişim sürecinde, bu süreçten bağımsız bir ilerleyişe rastlanılmamıştır. 


\section{UYUMLU TASARIMDA YAYINCILARIN YOL HARITALARI}

Uyumlu tasarımın kendisini yayıncılar için ortaya çıkardığı önemli alanlardan biriyle, yol haritalarında karşılaşıımaktadır. Her yazılımsal sürecin arkasında bir çerçeve tasarım süreci, yol haritası ile belirlenmiş sınırlar dâhilinde hareket etmektedir. Bu noktada, günümüz yayın ortamlarında pek çok farklı sistem kullanımı gündeme gelmektedir. Bu sistemler, ilgili internet sitelerini ortak dil prensibiyle bir kategoriye yerleştirebilmeyi sağlamaktadır. Böylece daha kuralı ve farklı işletim sistemlerince daha hızlı biçimde anlaşılabilir bir süreç yönetimi ortaya çıkmaktadır. İlgili ortak dili sağlayan unsurlar da, yine uyumlu tasarım süreci ile birlikte önce kendilerini kullanııının gereksinimlerine göre konumlandırmayı başarmış kuruluşlarca ortaya atılmıştır. Illgili konumlandırmaya önemli bir örnek, Twitter tarafından oluşturulmuş tasarım şablonlarını belirli kod dizilimleri ile oluşturmuş olan Bootstrap (t.y.) isimli ön yüz çerçeve sistemi sunan kütüphanedir. Ön yüzde, yani işlenen kodların görsel tasarıma yansıyan kısmında kullanılan bu kütüphanelerde, hangi sütun ve satırların hangi işlemler dâhilinde hareket sahası bulacağı belirli kurallara dayandırımaktadır. Sayfalar, belirli aralıklara bölünmek suretiyle ayrı ayrı kümeler oluştururlar. Bu kümeler içerisinde yer alan birimler de, yine yerleştirilmesi istenen alt tasarım elemanları ile doldurulurlar. Bu tasarım elemanları, katlanabilir veya açılabilir menüleri, yazı tiplerini, görsel galerilerini ve daha birçok farklı ürünü içerisinde barındırmaktadır. Tüm bu yapı, çapraz platformlarda uyum gösterme prensibi ile şekillendirilmiştir. Aynı zamanda çözünürlükten bağımsız olarak, görüntüyü rahatsı edici bir bozulma oluşturmadan, kullanııının deneyimine en uygun biçimde dağıtma prensibi üzerine çalışmaktadır. Dolayısıyla, kütüphanede yer alan her bir kod parçası, özelleştirilebilir olmaktadır. Bu da, tasarımcılara özgür biçimde farklı ürünler ortaya koyabilme fırsatı sağlamaktadır. Bootstrap'in daha gelişmiş halleri olarak da söylenebilecek alternatif diğer önemli sistemler ise React ve Angular olarak gösterebilmektedir. React, Facebook tarafından sunulmuş olan bununla birlikte başka ek kütüphanelere daha ihtiyaç duyan bir yapıda bulunmaktadır. Yine aynı şekilde Facebook'un yanında Instagram ve Reddit gibi sosyal medya uygulamaları ile birlikte Netflix platformunun bu sistemi kullandığı bilinmektedir (Coder Academy, 2016). Angular ise geliştirici ekibinde Google'ın yer aldığı bir sistemdir. Angular'ın önemli bir özelliği başta ABC News ve Forbes olmak üzere pek çok internet yayıncılığı kuruluşu tarafından kullanılıyor oluşudur (Polepeddi, 2019). İlgili tüm bu internet sitelerindeki tasarım odaklı süreçler, yayıncı kuruluşların hem taşınabilir hem masaüstü cihazlardaki varlıklarını sürdürebilmeleri adına oldukça önemli bir yer kaplamaktadır. Bununla birlikte, haber ve benzeri yayın içeriklerinin yanında 
etkileşimin arttığı ya da artması gereken noktalarda başka alternatifler de söz konusu olabilmektedir. Seçim sonuçları, popülasyona ve demografiye yönelik veriler, spor müsabakalarının hareketli animasyonları ve benzeri pek çok veri odaklı içeriğin diğer adıyla infografiğin çeşitli alternatiflerle güçlendirilmesi gerekebilmektedir. Bu noktada farklı alternatifler sunan kütüphaneler de tercih edilebilmektedir. Örneğin, IBM tarafından geliştirilen tasarım dili IBM Design Language ya da bu dilin kapsadığı sistem ismiyle Carbon (t.y.), bu noktada devreye girmektedir. React ve Angular kütüphaneleri ile ortaklaşa çalışabilen bu sistemde, tasarımcılar verileri işleyebilmekte ve hareketli görseller vasıtasıyla aktarabilmektedirler.

Teknik bağlamın dışında kalan yapılarda, yayın kuruluşlarının kendi yol haritalarını ve altyapı sistemlerini kurdukları örneklerle karşılaşılabilmektedir. Bunların önemli temsilcileri olarak The Dallas Morning News ve BBC isimleri belirtilebilir. Bu iki yayıncının en temel özellikleri, yayın protokolü için tıpkı Microsoft'un Fluent Design System (Akıcı Tasarım Sistemi) ve Google'ın Material Design (Mazeleme Tasarımı) isimli tasarım protokollerine benzer protokoller oluşturmuş olmalarıdır. The Dallas Morning News, Morris, Smith ve Pecanha (2005) tarafından kaleme alınmış bir grafik rehberine sahiptir. Bu rehber, internet sitesi dışında kalan yayın faaliyetinin tüm fiziksel üretim sürecini kapsayan bir yol haritası olma görevi görmüştür. Tüm üretim süreci, kullanılacak yazı tiplerinin detaylandırmasından, iş akış çizelgelerine kadar geniş perspektifli bir protokole sahiptir. Renk kodlarının sınıflandırmaları ve yine aynı şekilde sütun ve satır ölçüleri, başlık ve paragraf-metin hizalamaları gibi çok sayıda değişkenin standardizasyona tabii tutulduğu görülmektedir. Bu rehberin yeni medya teknolojileri kapsamında yorumlanmış hali BBC tarafından üretilmiş olan Global Experience Language (GEL, Küresel Deneyim Dili) uygulamasında görülmektedir (Cesal, 2020). Tüm pencere tipleri, menü ve animasyon ayarlamaları, yazı ve karakter tipleri, kullanılacak başlık ve görsel büyüklükleri gibi verilerin tamamı bu dil kapsamında standardize edilmiştir. Uyumlu tasarım sürecinin getirdiği en önemli yeniliklerden olan açlır kapanır menüler ve bu menülerin diğer alt bağlantı modüllerinin tamamı yine aynı şekilde bu dil kapsamında sunulmuştur (BBC, t.y.-b). Bu iki yayın kuruluşu üzerinden yola çıkarak, yeni medya teknolojilerinin kapsama sahasının her geçen yıl daha da ilerlediği ve yaşanan değişim süreci sonrasında yazılımsal unsurların yayıncılık alanında da ana belirleyiciler olmaya başladığı söylenebilmektedir. 


\section{SONUÇ VE ÖNERILER}

Çalışma kapsamında elde edilen bulgular uyarınca, yeni medya ve çevresinde inşa edilen teknik gelişim sürecinin, yayın faaliyetinde bulunan kuruluşları etkisi altına aldığı görülmüştür. Zamanla, birbirlerinden kopuk olarak internet üzerinde konumlanan kitle iletişim araçlarının bir noktada yine yazııımsal faktörler doğrultusunda bir araya gelmeye başladığı görülmektedir. Bunun için de, kullanıcıların deneyimlediği ya da deneyimleyeceği ortamlara yönelik gerçekleştirilmiş sistemsel yol haritalarının oldukça önemli olduğu anlaşılmaktadır. Uyumlu tasarım da bu anlamda sadece bir arayış noktası olmamış; aynı zamanda ulaşılması gereken yapılardan biri haline gelmiştir. Çalışmada elde edilen bir diğer sonuçta da, giderek taşınabilir cihaz sürecini daha da hızlandıran yayın kuruluşlarının, gelecek bir sonraki teknolojiye, yeni medyanın aktörlerinin yol göstericiliğinde hazırlandıkları görülmektedir. Bu çıkarımın Türkiye özelinde kendisini nasıl gösterdiğinin anlaşılabilmesi adına, gelecek çalışmalarda yurtiçindeki tüm kitle iletişim araçlarının aktörü konumundaki kurumlarının uyumlu tasarım süreçlerinin incelenmesi önerilmektedir. Kullanılan altyapıların ve izledikleri yol haritalarının, ulusal anlamda nasıl bir teknik yayıncılık anlayışına sahip olunacağını kavramak ve ilerideki teknik gelişimin ihtiyaçlarını analiz edebilmek için önemli veriler sunacağı düşünülmektedir. Önerilen diğer konu da, taşınabilir cihaz performansları bakımından indirilebilir içerik ortamları ile çevrimiçi internet siteleri üzerinden ulaşılabilen veri noktalarının karşılaştııılmasıdır. Kullanıcıların, uyumlu tasarım süreçlerinin ne kadarından haberdar olduklarının öğrenilmesinin, sonraki geliştirme süreçlerinde kullanııının ilgili sürece dâhil edilmesi bakımından ne tür bir etkiye sahip olduğu hakkında bilgi vereceği varsayılmaktadır.

\section{EXTENDED ABSTRACT}

Technology affects different markets in different ways. The effects can create various signals for market players, customers, and consumers. Although this might be obvious, hidden sub-effects of technology can help create more realistic future assumptions. For example, the relationship between internet technologies and mass media tools provides an important case to understand these subeffects.

Large media corporations are currently trying to find a way to adapt and integrate their business models into internet technologies. Overall, new ways are occurring on the market each day, which keep changing even the basic points through technical perspectives. Responsiveness has been one of those 
points which media users face. This describes the adaptation progress of actions taking part on mass media outputs such as news, sounds, videos, or any other shared social media. This progress can be defined as a technical way to combine and execute all media systems in similar devices at once, using the same programming code structure and basic design patterns.

In this study, a broad range of literature was reviewed to investigate the development processes of mass media around responsive mechanisms. It was assumed that both mass media and Web 2.0based design features affected each other, and responsive design - as an element of Web 2.0 - is the bridge to connect different mass media technologies. To understand what has helped to develop such a bridge, as e.g. responsive websites, this study examines the beginning of internet connections for mass media tools.

Marcotte (2010) coined the term "responsive design" to explain and structure CSS and HTML code (Bryant \& Jones, 2012, s. 37). This was a bridge to merge all informative connections into one through websites. But it wasn't the first attempt to gain power over web technologies. Many different platforms and developers worked on paving this path. At first, mass media companies tried to create an internet independently from each other's publishing or streaming areas. Television went on its own way, while newspapers went on another. 1971 was the starting point of interactive television. The BBC led several attempts to message-based boards for TV. This technology led to teletext as we know it today (Carlson, 2003, s. 33; BBC, t.y.-a). Until the end of the 1980s, television showed significant development progress as an interactive environment system. Then, other platforms followed TV to gain an active role in modern technology. In 1992, the newspaper The Chicago Tribune entered a critical partnership with AOL to release the first online newspaper system (Cassidy, 2005). Two years later, another online newspaper called the Palo Alto Weekly (Carlson, 2003, s. 49-50) followed. Then, in 1993 Internet Talk Radio started to broadcast online (Sawhney \& Lee, 2005, s. 400; McKinney, Barnas, \& Golub, 1994, s. 634; Ginsburg, 1997). These attempts were followed by many others in many different countries between 1990 and 2000. But there is a new perspective which needs to be mentioned. As a social network platform, Geocities started to gain popularity in 1994 (Milligan, 2017). It changed the use of the internet from accessing information to letting people interact with each other while reading or watching web-based files. Until 2006, several websites of press and other media organizations tried to use the interactive power of tools like Geocities did. But an improvement of system, called Web 2.0 changed 
their core ideas and methods. This allowed organization which had power over media environments to create their own design templates and languages. Hence, design has emerged as a powerful tool to express an organization's main structure. Change observed in the market has become a dominant effect on mass media together with the design languages that organizations use.

The literature review has shown that during the mid-1990s there was an active effort to position mass media systems as a monolithic, solid structure. Design efforts were the key component to making this happen. On the road, all sides from different kinds of areas such as radio, television, and newspaper markets were affected differently by technical methodologies. However, in the following years, a technical perspective of responsiveness has opened new windows to enrich interactions between not just mass media producers, but also its users. As a result, there are two key findings obtained from the literature review. First, it was determined that the development process in programming-based technologies has forwarded mass media elements to merge more in a singular position. Although social media presents alternative information points and expands media tools, organizations are still in charge but in a merged state together with social media. Second, traditional mass media organizations started to affect the new media environment and their innovations. This result supports the idea of a bridge effect that connects all sides of media segments.

\section{KAYNAKÇA}

Almeida, F., \& Monteiro, J. (2017). The Role of Responsive Design in Web Development. Webology, 14(2), 48-65.

Alston, P. (2012). Teaching Mobile Web Application Development: Challenges Faced And Lessons Learned. Proceedings of the 13th annual conference on Information technology education (s. 239244). Calgary Alberta : Association for Computing Machinery.

BBC. (t.y.-a). History of the BBC: CEEFAX: world's first teletext service. 09 15, 2020 tarihinde BBC: https://www.bbc.com/historyofthebbc/anniversaries/september/ceefax adresinden alındı

BBC. (t.y.-b). Global Experience Language. 09 15, 2020 tarihinde BBC: https://www.bbc.co.uk/gel adresinden alındı

Bernstein, G. L., \& Klemmer, S. (2014). Towards Responsive Retargeting of Existing Websites. 27th annual ACM symposium on User interface software and technology - UIST (s. 119-120). Honolulu: ACM. 
Bilgi Teknolojileri ve Illetişim Kurumu. (2020, 07 16). Türkiye Elektronik Haberleşme Sektörü: Üç Aylık Pazar Verileri Raporu. 09 15, 2020 tarihinde BTK: https://www.btk.gov.tr/uploads/pages/pazarverileri/2020-1-16-07-20-kurum-disi.pd adresinden alındı

Bootstrap. (t.y.). Documentation. 09 15, 2020 tarihinde Get Bootstrap: https:/getbootstrap.com/ adresinden alındı

Bryant, J., \& Jones, M. (2012). Pro HTML5 Performance. APress.

Built With. (2021, 02 18). CMS Usage Distribution in the Top 1 Million Sites. 02 24, 2021 tarihinde Built With: https://trends.builtwith.com/cms adresinden alındı

Carbon Design System. (t.y.). Get Started. 09 15, 2020 tarihinde Carbon Design System: https://www.carbondesignsystem.com/developing/get-started adresinden alındı

Carlson, D. (2003). History of Online Journalism. K. Kawamoto (Dü.) içinde, Digital Journalism: Emerging Media and the Changing Horizons of Journalism (s. 31-55). Oxford, Birleşik Krallık: Rowman \& Littlefield Publishers Inc.

Cassidy, W. P. (2005). Variations on a Theme: The Professional Role Conceptions of Print and Online Newspaper Journalists. J\&MC Quarterly, 82(2), 264-280.

Cesal, A. (2020, 07 10). What Are Data Visualization Style Guidelines? 09 15, 2020 tarihinde Medium: Nighingale: https://medium.com/nightingale/style-guidelines-92ebe166addc adresinden alındı

Clarke, A. (2010). Hardboiled Web Design. Stanwell Road-Penarth : Five Simple Steps.

Coder Academy. (2016, 06 10). Top 32 Sites Built With ReactJS. 09 15, 2020 tarihinde Coder Academy: https://medium.com/@coderacademy/32-sites-built-with-reactjs-172e3a4bed81 adresinden alındı

Derrick, J. (2016, 07 25). Remember When Yahoo Turned Down $\$ 1$ Million To Buy Google? 09 07, 2020 tarihinde Yahoo Finance: https://finance.yahoo.com/news/remember-yahoo-turned-down-1132805083.html adresinden alındı

Foley, S. (2011, 10 23). Yahoo rejects Microsoft's advances and seals advertising deal with Google. 0907 , 2020 tarihinde Independent: Business News: https://www.independent.co.uk/news/business/news/yahoo-rejects-microsofts-advancesand-seals-advertising-deal-with-google-846337.html adresinden alındı

Gibbs, S., Hoch, M., Le Van Gong, H., Rafey, R. A., \& Wang, S. (2001). Broadcast Games and Digital Television. International Game Technology Conference. Hong Kong.

Ginsburg, L. (1997, 07 01). Contrarian Libertarian. 09 15, 2020 tarihinde Wired: https://www.wired.com/1997/07/malamud/ adresinden alındı 
Glassman, N., \& Shen, P. (2014). One Site Fits All: Responsive Web Design. Journal of Electronic Resources in Medical Libraries, 11(2), 78-90.

Gönenç, Ö. (2003). İnternet ve Türkiye'deki Gelişimi. İstanbul Üniversitesi Iletişim Fakültesi Dergisi , 87-98.

Graham Longo, R. (2012, 03 05). Mobile First: What Does It Mean? 04 30, 2020 tarihinde UX Matters: http://www.uxmatters.com/mt/archives/2012/03/mobile-first-what-does-it-mean.php adresinden alındı

Groth, A., \& Haslwanter, D. (2016). Efficiency, effectiveness, and satisfaction of responsive mobile tourism websites: a mobile usability study. Information Technology \& Tourism, 16(2), 201-228.

Hatipoğlu, S. (2009, Ağustos). Hayatın Sesini Aç. Radyovizyon(3), s. 45-46.

Heilmann, C. (2009, 02 09). Graceful degradation versus progressive enhancement - Dev.Opera. 04 30, 2020 tarihinde Github: Mathias Bynens: https://github.com/operasoftware/devopera-staticbackup/blob/master/http/dev.opera.com/articles/view/graceful-degradation-progressiveenhancement/index.html adresinden alındı

Hughes, C. J., Armstrong, M., Jones, R., \& Crabb, M. (2015). Responsive Design for Personalised Subtitles. 12th Web for All Conference - W4A, 8. Florence.

ітÜ kiO. (2020, 04 27). Üniversite Radyoculuğunun Ilklerinde Onun Imzası Var: IтÜ Radyosu. 09 15, 2020 tarihinde iтÜ Haberler: https://haberler.itu.edu.tr/haberdetay/2020/04/27/universiteradyoculugunun-i-Iklerinde-onun-i-mzas\%C4\%B1-var-i-tu-radyosu adresinden alındı

Kharpal, A. (2017, 06 13). Verizon completes its $\$ 4.48$ billion acquisition of Yahoo; Marissa Mayer leaves with $\$ 23$ million. 09 07, 2020 tarihinde CNBC: Tech: https://www.cnbc.com/2017/06/13/verizoncompletes-yahoo-acquisition-marissa-mayer-resigns.html adresinden alındı

Kim, B. $(2013,09)$. Responsive Web Design, Discoverability, and Mobile Challange. Library Technology Reports: The Library Mobile Experience: Practices and User Expectations, 49(6).

Kinugasa, S., Motohashi, K., Yeong-Wha, S. W., \& Terada, S. (2010). Empirical Study of IPTV Diffusion: Comparison between Japan and Korea. The Research Institute of Economy, Trade and Industry Discussion Paper Series(10-E-021). Japonya. 09 11, 2020 tarihinde https://www.rieti.go.jp/jp/publications/dp/10e021.pdf adresinden alındı

Kuhna, M., Kivelä, I.-M., \& Oittinen, P. (2012). Semi-Automated Magazine Layout Using Content-based Image Features. 20th ACM international conference on Multimedia (s. 379-388). Nara: ACM.

Laakaniemi, R. (1981). The Computer Connection: America's First Computer-Delivered Newspaper. Newspaper Research Journal, 2(4), 61-68. 
Ma, M., Wilkes-Gibbs, D., \& Kaplan, A. (2004). IDTV Broadcast Applications for a Handheld Device. IEEE International Conference on Communications (s. 85-89). Paris: IEEE.

Marcotte, E. (2010, 05 25). Responsive Web Design. 04 30, 2020 tarihinde A List Apart: https://alistapart.com/article/responsive-web-design adresinden alındı

Mclntosh, N. (2003, 02 18). Google buys Blogger web service. 09 07, 2020 tarihinde The Guardian: https://www.theguardian.com/business/2003/feb/18/digitalmedia.citynews adresinden alındı

McKinney, W. P., Barnas, G. P., \& Golub, R. M. (1994). "The medical applications of the internet", Journal of General Internal Medicine. Journal of General Internal Medicine, 9(11), 627-634.

Milligan, I. (2017). Welcome to the web: The online community of GeoCities during the early years of the World Wide Web. N. Brügger, \& R. Schroeder (Dü) içinde, The Web as History (s. 137-158). Londra: UCL Press.

Milliyet Gazetesi. (1996, 12 25). Milliyet Internet Arşiv - Geçmiş Sayılar. 09 15, 2020 tarihinde Milliyet: https://web.archive.org/web/19970225052055/http://www.milliyet.com.tr/1996/12/25/arsi vindex.html adresinden alındı

Morris, C., Smith, L., \& Pecanha, S. (2005). The Dallas Morning News: Graphics Stylebook,. 09 15, 2020 tarihinde https://info.sice.indiana.edu/ katy/S637-S11/SDallasMorningNewsGraphicsStylebook.pdf adresinden alındı

Nebeling, M., \& Norrie, M. (2013). Responsive Design and Development: Mothods, Technologies and Current Issues. F. Daniel, P. Dolog, \& Q. Li (Dü.), Web Engineering, 13th International Conference ICWE içinde (s. 510-513). Aalborg: Springer Verlag.

Parker, T., Toland, P., Jehl, S., \& Costello Wachs, M. (2010). Designing With Progressive Enhancement: Building the Web That Works for Everyone. Kaliforniya-Berkeley: New Riders Pub.

Perakakis, E., \& Ghinea, G. (2015). Responsive web design for the internet connected TV: The answer to more smart TV content? IEEE 5th International Conference on Consumer Electronics (s. 38-42). Berlin: IEEE.

Polepeddi, L. (2019). Communication. 09 15, 2020 tarihinde Made With Angular: https://www.madewithangular.com/categories/communication adresinden alındı

Sarkis, M., Concolato, C., \& Dufourd, J.-C. (2017). A multi-screen refactoring system for video-centric web applications. Multimedia Tools and Applications, 1-28.

Sawhney, H., \& Lee, S. (2005). Arenas of innovation: understanding new configurational potentialities of communication technologies. Media, Culture \& Society, 27(3), 391-414. 
Schneider, G., \& Bruton, C. (2006). Emerging Revenue Models in Social Networking Portals. Proceedings of the Academy of Strategic E-Commerce: Allied Academies International Conference, 5.

Somers, M., \& Paul, J. M. (2008). Webpage-Based Benchmarks for Mobile Device Design. Asia and South Pacific Design Automation Conference (s. 795-800). Seul: IEEE.

Tomas, K. B. (2013). Virutal Reality: Why Magazines Should Adopt a Mobile-First Publishing Strategy. Publishing Research Quarterly, 29(4), 301-317.

Türkiye Bilimler Akademisi. (t.y.-a). 'standalone'. 09 08, 2020 tarihinde TÜBA: Bilim Terimleri Sözlüğü: http://www.tubaterim.gov.tr adresinden alındı

Türkiye Bilimler Akademisi. (t.y.-b). 'responsive design'. TÜBA: Bilim Terimleri Sözlüğü: http://www.tubaterim.gov.tr adresinden alındı

van Dijk, J. A., \& Vos, L. d. (2001). Searching for the Holy Grail: Images of Interactive Television. New Media \& Society, 3(4), 443-465.

van Vliet, H. (2002, 06 16). Where Television and Internet meet...: New experiences for rich media. 09 11, 2020 tarihinde E-View: https://web.archive.org/web/20020616131459/http://comcom.kub.nl/eview/02-1/vliet.htm adresinden alındı

Voutilainen, J.-P., Salonen, J., \& Mikkonen, T. (2015). On the Design of a Responsive User Interface for a Multi-device Web Service. 2nd ACM International Conference on Mobile Software Engineering and Systems (s. 60-63). Floransa: IEEE.

W3Techs. (2021, 02 10). Usage statistics of content management systems. 02 24, 2021 tarihinde W3Techs: https://w3techs.com/technologies/overview/content_management adresinden alındı

Walsh, T. A., McMinn, P., \& Kapfhammer, G. M. (2015). Automatic Detection of Potential Layout Faults Following Changes to Responsive Web Pages", . 30th IEEE/ACM International Conference on Automated Software Engineering (s. 709-714). Nebraska: IEEE.

Xiao, Y., Du, X., Zhang, J., Hu, F., \& Guizani, S. (2007, 11). Internet Protocol Television (IPTV): The Killer Application for the Next-Generation Internet. IEEE Communications Magazine, 45, s. 126-134. 